\section{Diabetic Rats Present High Mean Platelet Count in the Presence of Oral Infections}

Luciana Louzada Ferreira1, João Eduardo Gomes-Filho', Dóris Hissako Sumida², Suely Regina Mogami Bonfim³3, Gustavo Sivieri-Araújo', Gustav Guimarães ${ }^{1,4}$, Luciano Tavares Angelo Cintra ${ }^{1}$

\begin{abstract}
Platelet count is associated with inflammatory diseases like diabetes mellitus (DM), which in turn, is related in a bidirectional manner with apical periodontitis and periodontal disease. The aim of this study was to evaluate the effects of apical periodontitis and/or periodontal disease on mean platelet count in a rat model of diabetes mellitus. Eighty Wistar rats were randomly divided into 8 groups $(n=10)$ : control $(C)$, apical periodontitis $(A P)$, periodontal disease (PD), apical periodontitis with periodontal disease (AP-PD), diabetes mellitus (DM), diabetes mellitus with apical periodontitis (DM-AP), diabetes mellitus with periodontal disease (DM-PD) and diabetes mellitus with apical periodontitis and periodontal disease (DM-AP-PD). Rats were anesthetized and DM was induced with a single dose of streptozotocin diluted in citrate buffer solution. After 6 days, the DM was confirmed. The animals were sedated and apical periodontitis was induced by dental exposure and periodontal disease was induced by periodontal ligature. After 30 days, animals were anesthetized and the blood was collected by cardiac puncture. Samples were processed and the mean platelet count was obtained. Data were tabulated and subjected to statistical analysis $(p<0.05)$. Diabetic rats had higher mean glycemic levels compared with nondiabetic rats at 6 and 36 days after DM induction $(p<0.05)$. The DM-PD and DM-PD-AP groups showed increased mean platelet count compared to control and AP groups $(p<0.05)$. The periodontal disease alone or associated with apical periodontitis influence mean platelet count in a rat model of diabetes mellitus.
\end{abstract}

\author{
'Department of Endodontics, \\ Araçatuba School of Dentistry, \\ UNESP - Univ Estadual Paulista, \\ Araçatuba, SP, Brazil \\ ${ }^{2}$ Department of Basic Science, \\ Araçatuba School of Dentistry, \\ UNESP - Univ Estadual Paulista, \\ Araçatuba, SP, Brazil \\ ${ }^{3}$ Department of Clinic and \\ Surgery and Animal Reproduction, \\ Araçatuba School of Veterinary \\ Medicine, UNESP - Univ Estadual \\ Paulista, Araçatuba, SP, Brazil \\ ${ }^{4}$ Department of Dentistry, \\ UNISL - Centro Universitário São \\ Lucas, Porto Velho, RO, Brazil \\ Correspondence: Dr. Luciano Tavares \\ Angelo Cintra, Rua José Bonifácio, \\ 1193, 16015-050 Araçatuba, SP, \\ Brasil. Tel: +55-18-3636-2867. \\ e-mail: lucianocintra@foa.unesp.br
}

Key Words: apical periodontitis, periodontal disease, diabetes mellitus, platelet count.

\section{Introduction}

Diabetes mellitus (DM) is a complex syndrome characterized by chronic hyperglycemia responsible for complications that affect vital organs (1). Platelets are the smallest blood cells and sensitive indicators of health disturbances (2). Platelet count is an indicator of platelet activation, which shows a close relationship with diseases prone to inflammation, such as DM and cardiovascular risk factors (3). Platelets are hyperactive and produce more thromboxane A2 in presence of DM (4). Some evidences have shown that DM morbidity and mortality are associated with coronary complications due to altered morphology and dysfunction (4).

The increase in platelet count is correlated with increased adhesiveness, aggregation and greater exposure of glycoprotein receptor on platelet membrane and increase in binding of fibrinogen, which could alter platelet metabolism and inter signaling pathway (5). Studies showed that platelet count is a predictor of insulin resistance in patients with DM type 2 (6) and high mean platelet count for diabetic individuals presents significant difference compared to healthy individuals (7). However, a previous study showed that platelet count in blood collection of patients with DM type 2 was slightly lower than in the control group (8), or did not present any statistical difference (1), showing that the activation of platelets in DM does not depend on glycemic control diabetes (8).

It is also known that DM is associated with severe pulp and periodontal infections (9-11). Several studies have shown that localized inflammation in the oral cavity is associated with high levels of systemic markers, focusing on its relationship with periodontal disease (PD), DM and cardiovascular diseases (9). A study with diabetic rats showed that PD and apical periodontitis (AP) might contribute to insulin signaling decrease resulting in insulin resistance (12), especially due to the high levels of pro-inflammatory cytokines (12). Endodontic infections were reported to be more aggressive and destructive in individuals with DM, due to its uncontrolled blood glucose levels, resulting in poor healing (9).

A previous study evaluated the association of platelet count and PD (13); however, to the best knowledge of the authors, there are no studies evaluating the association of DM, platelet count and oral infections. The aim of this study was to evaluate the effects of apical periodontitis and/or periodontal disease on mean platelet count in a rat 
model of diabetes mellitus.

\section{Material and Methods}

The experimental protocol was approved by the Institutional Ethics Committee of UNESP - Univ Estadual Paulista (Process 00539) and was conducted in accordance with relevant guidelines.

\section{Experimental Animals and DM Induction}

Eighty male Wistar rats (Rattus albinus albinus), weighing 200-250 g were used in this study. The animals were housed in temperature-controlled rooms with ad libitum access to water and food.

After the animals fasted overnight (14-16 h), blood samples were collected by the tail tip method and fasting blood glucose concentrations were measured (day 0 ) by an automatic blood glucose monitoring system (Accu-Check ${ }^{\circledR}$ Performa; Roche-Diagnostics Corporation, Indianapolis, IN, USA). The animals were then randomly divided in the following 8 groups ( $n=10)$ : control (C), apical periodontitis $(A P)$, periodontal disease $(P D)$, apical periodontitis with periodontal disease (AP-PD), diabetes mellitus (DM), diabetes mellitus with apical periodontitis (DM-AP), diabetes mellitus with periodontal disease (DM-PD) and diabetes mellitus with apical periodontitis and periodontal disease (DM-AP-PD). The anesthesia was administered by intramuscular injection of ketamine $\left(87 \mathrm{mg} / \mathrm{kg}\right.$, Francotar ${ }^{\circledR}$; Virbac do Brasil Ind e Com Ltda; Roseira, SP, Brazil) and xylazine $\left(13 \mathrm{mg} / \mathrm{kg}\right.$, Rompum ${ }^{\circledR}$; Bayer SA, São Paulo, $S P, B r a z i l)$. The groups $C, A P, P D$ and AP-PD received an injection in the penile vein containing $0.01 \mathrm{~mol} / \mathrm{L}$ citrate buffer solution $4.5 \mathrm{pH}$, and the groups DM, DM-AP, DM$\mathrm{PD}$ and DM-AP-PD received an injection in the penile vein containing streptozotocin (Sigma-

Aldrich Corp, St Louis, MO, USA) dissolved in a citrate buffer solution at $35 \mathrm{mg} / \mathrm{kg}$ for the experimental induction of diabetes (10).

Six days after diabetes induction (day 6), blood samples were collected to determine blood glucose levels of all animals. The animals with more than $200 \mathrm{mg} / \mathrm{dL}$ were used in the DM group. Once the hyperglycemia was confirmed, all animals were sedated for the induction of oral infections.

\section{Induction of oral infections}

To induce the AP, surgical round burs were used to expose the dental pulp on the mesial surface of right maxillary first molars (LN Long Neck all groups bur, Maillefer, Dentsply Ind e Com LTDA, Petrópolis, Brazil) in the groups AP, AP-PD, DM-AP, DM-AP-DP. The PD was induced using sterile silk ligatures (Ethicon; Johnson and Johnson, São Paulo, SP, Brazil) tied around the maxillary left second molars in the groups PD, AP-PD, DM-PD, DMAP-PD (11). Thirty days after oral infections induction, apical periodontitis and periodontal disease were confirmed radiographically.

\section{Collection of Blood Samples and Hematologic Analysis}

After thirty days, the animals were anesthetized with the same protocol and $5 \mathrm{~mL}$ of blood was collected by cardiac puncture of each rat for analysis of the blood glucose levels and platelet count (day 36 ). The samples were placed in 10\% EDTA $(10 \mu \mathrm{L})$, centrifuged and immediately transferred for processing to a technician who was blinded to the groups and mean platelet levels were measured. The analysis was performed with an automatic analyzer (ABX Micros ABC Vet; Horiba ABX Diagnostics, Montpellier, France). The results were subjected to analysis of variance (ANOVA) and Tukey test $(\mathrm{p}<0.05)$.

\section{Results}

The results of blood glucose levels and platelet count are in Table 1. Blood glucose was measured in all animals before diabetic induction (day 0 ) and similar glycemic levels were observed ( $p>0.05)$. On days 6 and 36, the blood glucose levels were compared with the normal ones, showing a statistical difference between nondiabetic (C) and diabetic rats (DM) with major difference after 30 days $(99.8 \pm 12.9$ and $304.5 \pm 43.9$ respectively) $(p<0.05)$. Higher level of blood glucose was observed in presence of DM and both oral infections (DM-AP-PD: 461.6 \pm 43.2 ).

Table 1. Mean and standard deviation (SD) of the blood glucose levels and platelet count of

\begin{tabular}{|c|c|c|c|c|c|}
\hline \multirow{2}{*}{ Groups } & \multicolumn{3}{|c|}{$\begin{array}{l}\text { Blood Glucose }(\mathrm{mg} / \mathrm{dL}) \\
\left(\text { Mean } \pm \mathrm{SD}^{*}\right)\end{array}$} & \multirow{2}{*}{$\begin{array}{c}\begin{array}{c}\text { Platelet Count } \\
\left(10^{9} / \mathrm{L}\right)\left(\mathrm{Mean}_{ \pm} \mathrm{SD}^{*}\right)\end{array} \\
36 \text { day }\end{array}$} & \multirow[t]{2}{*}{$\mathrm{n}$} \\
\hline & 0 day & 6 day & 36 day & & \\
\hline $\mathrm{C}$ & $80.1 \pm 06.1^{\mathrm{a}}$ & $103.9 \pm 11.7^{\mathrm{a}}$ & $99.8 \pm 12.9^{a}$ & $29.3 \pm 8.1^{\mathrm{a}}$ & 10 \\
\hline $\mathrm{AP}$ & $81.8 \pm 11.0^{\mathrm{a}}$ & $101.6 \pm 11.2^{\mathrm{a}}$ & $102.2 \pm 17.3^{\mathrm{a}}$ & $29.5 \pm 3.6^{\mathrm{a}}$ & 10 \\
\hline PD & $79.6 \pm 09.8^{a}$ & $105.9 \pm 12.7^{\mathrm{a}}$ & $100.8 \pm 10.5^{a}$ & $33.3 \pm 7.1^{\mathrm{ab}}$ & 10 \\
\hline AP-PD & $82.3 \pm 07.7^{a}$ & $104.4 \pm 10.0^{\mathrm{a}}$ & $97.6 \pm 18.7^{\mathrm{a}}$ & $33.8 \pm 7.2^{\mathrm{ab}}$ & 10 \\
\hline DM & $81.0 \pm 08.1^{\mathrm{a}}$ & $322.1 \pm 36.6^{b}$ & $304.5 \pm 43.9^{b}$ & $32.7 \pm 4.2^{\mathrm{ab}}$ & 10 \\
\hline DM-AP & $78.2 \pm 10.5^{\mathrm{a}}$ & $319.7 \pm 31.5^{b}$ & $299.1 \pm 39.8^{\mathrm{b}}$ & $32.9 \pm 3.6^{\mathrm{ab}}$ & 10 \\
\hline DM-PD & $81.9 \pm 11.8^{\mathrm{a}}$ & $320.2 \pm 43.1^{\mathrm{b}}$ & $427.0 \pm 41.9^{\mathrm{bc}}$ & $38.6 \pm 3.1^{\mathrm{b}}$ & 10 \\
\hline DM-AP-PD & $82.5 \pm 08.1^{\mathrm{a}}$ & $321.1 \pm 39.2^{\mathrm{b}}$ & $461.6 \pm 43.2^{c}$ & $38.8 \pm 3.2^{\mathrm{b}}$ & 10 \\
\hline
\end{tabular}

*Different letters in the same column indicate statistically significant difference $(\mathrm{p}<0.05)$. 
Platelet count was performed once, in all animals, after 36 days from the start of experiment (Fig. 1). The mean platelet counts of diabetic rats with periodontal disease (DM-PD: $38.6 \pm 3.1$ ) and of diabetic rats with both periodontal and pulp disease (DM-AP-DP: $38.8 \pm 3.2$ ) results were significantly higher than control rats (C: $29.3 \pm 8.1)$ and nondiabetic rats with pulp infection (AP: $29.5 \pm 3.6)(p<0.05)$.

The nondiabetic rats had an increase of the platelet count in animals with periodontal disease (PD; $33.3 \pm 7.1$ ) and with both oral infections (AP-PD: $33.8 \pm 7.2$ ) compared to animals without infection (C: $29.3 \pm 8.1$ ) or with pulp disease (AP: $29.5 \pm 3.6$ ), but no statistical difference was observed $(p>0.05)$.

\section{Discussion}

This is the first study to assess the mean platelet count associated with diabetes, apical periodontitis and periodontal disease. The animals of this study were normoglycemic before induction, had uniform body weight and did not have glycosuria. DM was induced with streptozotocin, considered a safe drug used in clinical trials with a high rate of success in induction (9). The metabolism of these diabetic rats is similar to that of human diabetic$$
\text { experimental groups after } 36 \text { days. }
$$

The blood analysis is frequently used to evaluate the presence of an infection or inflammation, allowing the determination of when the periodontal disease affects the hematological parameters $(10,11)$. Recent studies showed the differences in hematologic parameters of normal rats compared to diabetic rats in the presence or not of AP and/or PD $(10,11)$ and in multiple foci of the apical periodontitis (14). This study compared nondiabetic and diabetic groups, both with or without pulp and periodontal disease. The mean blood glucose levels of diabetic rats

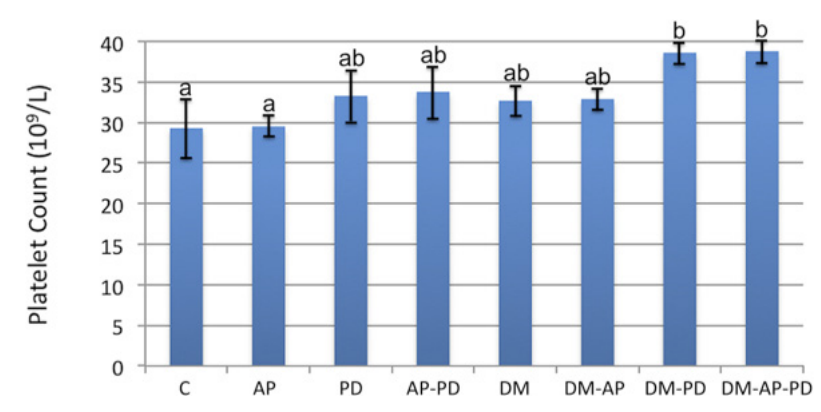

Figure 1. Distribution of mean platelet count $\left(\times 10^{9} / \mathrm{L}\right)$ according to the different groups. was approximately threefold higher than the nondiabetic $(p<0.05)$. In addition, the presence of oral infections increased blood glucose concentrations in diabetic rats and the results agree with previous studies $(10,11,14,15)$.

Studies offer evidence of enhanced activation or increased platelet activity in patients with DM $(1,4-8,16)$. Hyperglycemia may improve the platelet reactivity, inducing non-enzymatic glycation proteins on the platelet surface, due to the osmotic effect and protein activation (4). In recent studies, the diabetic group showed a higher mean platelet count compared to the nondiabetic group $(1,7)$. In addition, the conducted study showed that the DM-PD and DM-AP-PD groups had higher mean values of platelet count with statistical difference compared to $\mathrm{C}$ and $\mathrm{AP}$ groups.

This difference might be due to the presence of periodontal disease, which is well known to elevate the blood glucose levels, as shown by the present results and in the literature $(9,10,17,18)$. Hence, the platelet count may be dependent on several variables, as the mean of platelet survival, the platelet production rate and the turnover rate in DM (16). Prevalence of periodontal disease among patients with DM is higher than in the general population (17). It is an interrelationship, well established through a number of pathways and bidirectional (19). A study showed that loss of periodontal attachment and bone loss were higher in individuals with DM compared to nondiabetics (20).

Despite the periodontal disease, which causes a localized inflammation, there is the apical periodontitis, which is considered a health problem that requires more studies (21). A study confirmed the association between AP and $\mathrm{DM}$, showing that in nondiabetic animals, AP was able to cause alterations in insulin signaling and sensitivity (12); it was also observed in animals with more than one AP (14). The prevention of oral inflammatory diseases may prevent insulin resistance. However, the influence of blood glucose control on platelet count requires to be more investigated, especially in the presence of oral infections.

Another study revealed that lipid levels could influence the platelet counts (2) and other study observed that both PD and AP increase triglycerides levels in diabetic rats (15). This observation confirms that systemic health is influenced by endodontic infections when associated with PD or in multiple foci (14).

The present study evaluated the platelet count between healthy (C) and diabetic (DM) animals, observing that DM along oral infections alters the platelet parameters. Most researches that analyzed platelet count were conducted in human beings $(1,2,6,7)$, however the animal model might be advantageous, because it may be standardized to characterize several biological phenomena. The main function of platelets is the hemostasis, but they also play a 
role in inflammatory processes, and their numbers increase in chronic inflammation (22), like periodontal disease and diabetes, which was also observed in the present study. Patients with systemic diseases, like hematological disorders, are prone to present bone loss similar to $\mathrm{PD}$, which should be differentiated by assessing hematological parameters (23).

It is well known that platelets secrete and express a large number of crucial substances, like mediators of coagulation, inflammation, thrombosis and atherosclerosis (24). Patients with DM have an increased platelet activation compared to nondiabetics (25) and platelets with altered morphology are frequently associated with an increase of vascular complications in diabetic individuals (25).

In view of this important relationship between chronic infection and platelet count, more studies involving $\mathrm{DM}, \mathrm{PD}$ and $\mathrm{AP}$ are required to better understand this interrelationship and how it affect the platelets.

Based on this study, the authors found that the periodontal disease alone or associated with apical periodontitis influences mean platelet count in a rat model of diabetes mellitus.

\section{Resumo}

A contagem de plaquetas está associada a doenças inflamatórias como a diabetes mellitus (DM), que, por sua vez, está relacionada de forma bidirecional com periodontite apical e com a doença periodontal. 0 objetivo deste estudo foi avaliar os efeitos da periodontite apical e/ou da doença periodontal na contagem de plaquetas utilizando o modelo de rato para DM. Oitenta ratos Wistar foram divididos aleatoriamente em 8 grupos $(n=10)$ : controle $(C)$, periodontite apical (AP), doença periodontal (PD), periodontite apical com doença periodontal (AP-PD), diabetes mellitus (DM), diabetes mellitus com periodontite apical (DM-AP), diabetes mellitus com doença periodontal (DM-PD) e diabetes mellitus com periodontite apical e doença periodontal (DM-AP-PD). Os ratos foram anestesiados e a DM foi induzida com uma dose única de estreptozotocina diluída na solução tampão citrato. Após 6 dias, o DM foi confirmada. Os animais foram sedados e a periodontite apical foi induzida pela exposição dentária e a doença periodontal foi induzida por ligadura periodontal. Após 30 dias, os animais foram anestesiados e o sangue foi coletado por punção cardiaca. As amostras foram processadas e a contagem média de plaquetas foi obtida. Os dados foram tabulados e submetidos a análise estatística $(p<0,05)$. Os ratos diabéticos apresentaram niveis glicêmicos médios mais elevados em comparação com ratos não diabéticos aos 6 e 36 dias após a indução da DM $(p<0,05)$. Os grupos DM-PD e DM-PD-AP mostraram aumento da contagem média de plaquetas em comparação com os grupos controle e AP $(p<0,05)$. A doença periodontal isolada ou associada à periodontite apical influencia na contagem de plaquetas em modelo de rato para diabetes mellitus.

\section{References}

1. Demirtunc $R$, Duman D, Basar M, Bilgi M, Teomete M, Garip T. The relationship between glycemic control and platelet activity in type 2 diabetes mellitus. J Diabetes Complications 2009;23:89-94.

2. Peng L, Yang J, Lu X, Okada T, Kondo T, Ruan C, et al.. Effects of biological variations on platelet count in healthy subjects in China. Thromb Haemost 2004;91:367-372.

3. Carr ME. Diabetes mellitus: A hypercoagulable state. J Diabetes Complications 2001;15:44-54.

4. Vinik Al, Ebas T, Park TS, Nolan R, Pi Henger GL. Platelet dysfunction in type 2 diabetes. Diabetes Care 2001;24:1476-485.

5. Zuberi BF, Akhtar N, Afsar S. Comparison of mean platelet volume in patients with diabetes mellitus, impaired fasting glucose and nondiabetic subjects. Singapore Med J 2008;49:114-116.

6. Taniguchi A, Fukushima M, Seino $Y$, Sakai M, Yoshii S, Nagasaka $S$, et al.. Platelet count is independently associated with insulin resistance in non-obese Japanese type 2 diabetic patients. Metabolism 2003;52:1246-1249.

7. Akinzegun A, Olusola DA, Sarah JO, Olajumoke 0, Adewumi A, Majeed 0 , et al.. Mean platelet volume and platelet counts in type 2 diabetes: Mellitus on treatment and non-diabetic mellitus controls in Lagos, Nigeria. Pan Afr Med J 2014;12:18.

8. Wojszel J, Czyzewska J, Dymicka-Piekarska V, Matowicka-Karna J, Jakubowska I, Kemona H. Platelets activation in depending on glycaemic control in diabetes type 2. Pol Merkur Lekarski 2008;25:335339. (Polish).

9. Fouad AF. Diabetes mellitus as a modulating factor of endodontic infections. J Dent Educ 2003;67:459-467.

10. Cintra LT, Samuel RO, Facundo AC, Prieto AK, Sumida DH, Bomfim $S R$, et al.. Relationships between oral infections and blood glucose concentrations or HbA1c levels in normal and diabetic rats. Int Endod J 2014;47:228-237.

11. Cintra LT, da Silva Facundo AC, Prieto AK, Sumida DH, Narciso LG, Mogami Bomfim SR, et al.. Blood profile and histology in oral infections associated with diabetes. J Endod 2014;40:1139-1144.

12. Astolphi RD, Curbete MM, Colombo NH, Shirakashi DJ, Chiba FY, Prieto $A K$, et al. Periapical lesions decrease insulin signal and cause insulin resistance. J Endod 2013;39:648-652.

13. Wang $X$, Meng $H, X u$ Li, Chen Z, Shi D, Lv D. Mean platelet volume as an inflammatory marker in patients with severe periodontitis. Platelets 2015;26:67-71.

14. Cintra LT, Samuel RO, Azuma MM, de Queiróz AO, Ervolino E, Sumida DH, de Lima VM, Gomes-Filho JE. Multiple apical periodontitis influences serum levels of cytokines and nitric oxide. J Endod 2016; 42:747-751.

15. Cintra LT, da Silva Facundo AC, Azuma MM, Sumida DH, Astolphi RD, Bomfim SR, Narciso LG, et al.. Pulpal and periodontal diseases increase triglyceride levels in diabetic rats. Clin Oral Investig 2013;17:15951599.

16. Kodiatte TA, Manikyam UK, Rao SB, Jagadish TM, Reddy M, Lingaiah KM, et al.. Mean platelet volume in type 2 diabetes mellitus. J Lab Physicians 2012;4:5-9.

17. Taylor GW, Borgnakke WS. Periodontal disease: associations with diabetes, glycemic control and complications. Oral Dis. 2008;14:191203.

18. Cintra LTA, Samuel RO, Prieto AKC, Sumida DH, Dezan-Júnior E, Gomes-Filho JE. Oral health, diabetes, and body weight. Arch Oral Biol 2017;73:94-99.

19. Cintra LT, Samuel RO, Azuma MM, Ribeiro CP, Narciso LG, de Lima VM, et al.. Apical periodontitis and periodontal disease increase serum IL-17 levels in normoglycemic and diabetic rats. Clin Oral Investig 2014;18(9):2123-8

20. Shlossman M, Knowler WC, Pettitt DJ, Genco RJ. Type 2 diabetes mellitus and periodontal disease. J Am Dent Assoc 1990;121:532-536.

21. Bain JL, Lester SR, Henry WD, Naftel JP, Johnson RB. Effects of induced periapical abscesses on rat pregnancy outcomes. Arch Oral Biol 2009;54:162-171.

22. Klinger $\mathbf{M H}$, Jelkmann $\mathbf{W}$. Role of blood platelets in infection and inflammation. J Interferon Cytokine Res 2002;22:913-922.

23. Iqbal PS, Khan SN, Haris M, Narayanan M, Laju S, Kumar SS. Assessment of systematic inflammatory markers in patients with aggressive periodontitis. Int Oral Health 2015;7(Suppl 2):48-51.

24. Stokes KY, Granger DN. Platelets: a critical link between inflammation and microvascular dysfunction. J Physiol 2012;590:1023-1034.

25. Hekimsoy Z, Payzin B, Ornek T, Kandogan G. Mean platelet volume in type 2 diabetic patients. J Diabetes Complications 2004;18:173-176. 